\title{
Transient musical hallucinosis of central origin: a review and clinical study
}

\author{
P Paquier, P van Vugt, P Bal, P Cras, P M Parizel, J van Haesendonck, W Creten, \\ J J Martin
}

Antwerp University Hospital, Edegem, Belgium

Division of

Neurolinguistics

(Departments of

Neurology and ENT)

P Paquier

Department of

Radiology

P M Parizel

University of Antwerp

(UIA)

Unit of

Neurolinguistics

(Department of

Romance Philology)

$P$ van Vugt

Didascalia

(Department of

Didactics)

P Bal

Department of

Neurology

(Born-Bunge

Foundation)

P Cras

J J Martin

Department of ENT

$\mathrm{J}$ van Haesendonck

University of Antwerp (RUCA)

Laboratory for Medical Biophysics

W Creten

Correspondence to:

P Paquier, Division of

Neurolinguistics, Antwerp

University Hospital,

Wilrijkstraat 10, B-2650

Edegem, Belgium.

Received 5 November 1991 and in revised form

27 January 1992.

Accepted 6 February 1992

\begin{abstract}
A 52 year old, right handed, hearing impaired woman was admitted with headache and neck stiffiness. The only neuropsychological symptom was transient auditory perceptions in the left ear, which were musical, seemed familiar and were not influenced by verbal communication. CT and MRI showed a right subarachnoid haemorrhage, while brainstem auditory evoked potentials failed to reveal a brainstem lesion. In patients with organic cerebral disease, unilateral auditory hallucinations (AHs) may indicate a lesion in the contralateral hemisphere. However, according to this review the type of AHs (verbal versus musical) is not consistently associated with a cerebral lesion on either side.
\end{abstract}

$(\mathcal{F}$ Neurol Neurosurg Psychiatry 1992;55:1069-1073)

Auditory hallucinations (AHs) are auditory perceptions that occur in the absence of a corresponding external acoustic stimulus. 'The subject may or may not be fully aware of their imaginary nature. ${ }^{2-4} \mathrm{AHs}$ may be either elementary, for example, tinnitus, whistles, buzzing; or complex, such as music, voices or spoken words. ${ }^{56} \mathrm{AHs}$ may occur in isolated form, but some are associated with other hallucinations, for instance, visual or tactile. ${ }^{7-12}$ AHs may be perceived in either, or both ears. ${ }^{13-15}$ AHs have been described in different conditions: several psychiatric disorders, ${ }^{14_{16-30}}$ prolonged alcoholism, ${ }^{131-35}$ intoxication with drugs and other chemical agents, ${ }^{136-41}$ hypertension, ${ }^{42}$ several neurological disorders including migraine $e^{4344}$ and epilepsy, ${ }^{1245-49}$ and ear diseases. ${ }^{131650-53}$ The exact origin of AHs remains unclear. From a physiological and biochemical viewpoint, $\mathrm{AHs}$ may result from an abnormal brain excitability or a central disinhibitory factor, and from defective neurotransmission mechanisms. ${ }^{16}$ Some investigators ${ }^{1350-52}$ claim that neural or end organ disease alone is sufficient to produce AHs, thus postulating sensory deprivation to be the primary neurophysiological mechanism. Others $^{1653}$ maintain that a combination of peripheral and central dysfunction is required.

Hécaen and Ropert ${ }^{42}$ argued that lateralisation of AHs has no localising value in hallucinosis-that is, organic hallucinations of central origin, but would consistently implicate the worst ear when of otopathic origin. ${ }^{54}$
Bryant $^{55}$ stated that unilateral AHs are unquestionably due to unilateral ear disease. On the other hand, Bergman ${ }^{56}$ and Tanabe et al ${ }^{15}$ assumed that, in patients with organic brain disease, unilateral AHs could be considered a reliable indication of contralateral cerebral pathology. Berrios ${ }^{57}$ emphasised the important role played by the non-dominant hemisphere in the development of AHs of the musical type.

We studied a hearing impaired patient who developed a transient unilateral auditory hallucinosis in her ear, after a contralateral right subarachnoid haemorrhage.

\section{Case report}

A 52 year old, right handed woman of normal intelligence, presented with a previous medical history of multiple streptococcal sore throats complicated by acute rheumatic arthritis in childhood, a bilateral asymmetrical hearing loss, common migraine attacks for several years, a thrombo-embolic small intestinal infarct at the age of 49, gastrointestinal blood loss three months before the current event, a cardiac murmur based on mitral and aortic insufficiency, and hypertension. She admitted misuse of ergotalkaloids in the past. There was no history of overconsumption of alcohol.

In July 1988, she developed sudden right temporal headaches, progressively increasing and accompanied by an aching stiffness of the cervical spine. She looked ill, her right eye was slightly proptotic and she could not move her neck without great pain. She complained of paresthesiae in both upper limbs. Her blood pressure was $200 / 70 \mathrm{~mm} \mathrm{Hg}$. The rest of the neurological examination was normal. Paracetamol made her feel more comfortable.

Two days later, she started complaining of hearing music in her left ear. The music began suddenly at $11 \mathrm{pm}$, and was of such clarity that the patient thought that the radio was playing in the hospital corridor. After asking the nurses about the noise and then lying down on her better ear, she realised that the music was coming from inside her head. From that moment, she was always aware of the hallucinatory character of the musical perceptions. She described the music as popular classical, comprising orchestral arrangements with occasional vocals. She always recognised the tunes, which never bored her, although she sometimes wished for respite. They varied, and did not repeat themselves constantly. On rare occasions the contents of the hallucinations were distorted. Occasionally she heard bells 
chiming. She heard music when she awoke during the night, and when talking. The hallucinations occurred consistently, whether or not she used the hearing aid in her left ear. Only twice did she experience verbal hallucinations, comprising unknown voices speaking whole sentences which she could not understand. She did not experience hallucinations in other modalities. A few days later, the perceptions lessened in intensity, and were sometimes superseded by the ticking of a clock. The hallucinations disappeared gradually over the following days and three weeks after admission, the patient was free of them. On reexamination three months later, she had no complaints and her neurological status was normal.

Clinical investigation at the time of the hallucinations found no evidence of major psychiatric disorders. Laboratory tests did not disclose any intoxication.

A CT examination performed two days after admission demonstrated the hyperdense aspect of the right sylvian fissure and the right parietal sulci, presumably reflecting localised subarachnoid haemorrhage (SAH). A cerebral angiography showed vasospasm of the operculofrontal branches of the right middle cerebral artery. An aneurysm could not be identified. CT scans obtained 10 and 20 days after admission showed progressive disappearance of the hyperdense aspect of the right sylvian fissure. CT also disclosed the presence of old, bilateral capsuloputaminal lacunar infarcts. MRI revealed an area of increased signal intensity on a sagittal T1-weighted image through the right sylvian fissure, indicating subacute localised SAH (fig).

The day before the onset of the musical hallucinations, the EEG showed a symmetrical recording which was within normal limits. There was no evidence of epileptic activity nor of intoxication. Brainstem auditory evoked potentials (BAEP) at the time of the musical perceptions were normal.

Ear, nose and throat examination at the time of the auditory phenomena revealed a perceptive hearing loss on the left with a Fletcher

\footnotetext{
Figure Sagittal T1-weighted spin echo (short TR/short TE) MRI through the right sylvian fissure reveals a mild increase in signal intensity, presumably representing subacute haemorrhage (arrows). The high signal intensity represents methemoglobin formation.
}

index of $45 \mathrm{~dB}$, and a mixed perceptiveconductive hearing loss on the right, Fletcher index, $90 \mathrm{~dB}$. Otoscopy revealed a normal left drum and a posterior retracted drum on the right with a suspected incudostapedial dislocation. However, her otological status had remained unchanged since 1986.

Neurolinguistic and neuropsychological examinations at the time of the hallucinations failed to reveal any signs of aphasia, apraxia, agnosia, visuospatial disorders or hemispatial neglect. The Sound Lotto Test $^{58}$ excluded auditory agnosia. The patient had an IQ of 117 on Raven's ${ }^{59}$ standard progressive matrices.

\section{Discussion}

The patient's peri-acute neuropsychological symptomatology consisted of auditory hallucinatory perceptions in the absence of other major disorders of the higher mental functions. A comparison of her clinical picture, as well as personal and medical histories, with the different conditions that may cause AHs, allowed us to reject all but two.

Elementary and complex AHs have been reported in patients with a long history of progressive, sensorineural deafness in one or both ears, together with tinnitus. They are often of acute onset at the time of a further loss of hearing, and are experienced predominantly in the deaf or deafer ear. ${ }^{51546061}$ They are not associated with a psychosis. ${ }^{1357} \mathrm{AHs}$ in deafness seem to be permanent. ${ }^{52536263}$ It appears that musical hallucinations may disappear after some time, and be replaced by short but repetitive musical phrases, like the noise of a scratched record. ${ }^{57}$ Transitory, unilateral AHs have been mentioned in cases of acute ear disease. However, they parallel the evolution of the lesion, and gradually disappear on recovery. ${ }^{54}$

Our patient had suffered progressive bilateral hearing loss for many years, greater on the right, not associated with tinnitus. ENT investigation during admission failed to disclose an acute lesion, and neither otoscopic changes nor further hearing loss were found when compared with the previous examination. In other words, our patient's perceptions did not occur at the time of a further decrement in hearing. The auditory phenomena progressively disappeared over a period of two weeks, which is not compatible with the persistent nature of otogenic AHs. As our patient did not present with an acute ear disease, the gradual disappearance of her musical perceptions does not fit transitory AHs of otopathic origin. Moreover, she experienced the musical perceptions in her better ear, which is quite unusual in AHs of otopathic origin. ${ }^{54564}$ Finally, otogenic AHs seem to respond favourably to treatment with a hearing aid, ${ }^{6061}$ whereas our patient's auditory perceptions were not altered or abolished by her prosthesis. Consequently, these findings indicate that the origin of our patient's auditory perceptions cannot be reduced to a mere otopathy.

Transient AHs may also be encountered in several cerebral conditions. ${ }^{711} 154245495665-72$ 
Table 1 Reviewed cases of spontaneous musical or verbal AHs, or both, of central origin, whether or not associated with peripheral pathology, with exclusion of psychiatric and alcoholic aetiologies*

\begin{tabular}{|c|c|c|}
\hline Author(s) & $\begin{array}{l}\text { Number of relevant } \\
\text { cases }(n=118)\end{array}$ & Recorded cases \\
\hline Aizenberg et $a l^{16}$ & 1 & case 1 \\
\hline Bergman 56 & 12 & \\
\hline Berrios $^{57}$ & 1 & case 1 \\
\hline Berthier and Starkstein ${ }^{67}$ & 1 & \\
\hline Boza and Liggett ${ }^{74}$ & 1 & \\
\hline Cambier et al $^{5}$ & 4 & cases $1,2,3,4$ \\
\hline Courville $^{7}$ & 11 & $\begin{array}{l}\text { cases } 4663,15863,19244, \\
20125,22359,43,582, \\
22383,18273,15440,22539\end{array}$ \\
\hline Cummings et al ${ }^{68}$ & 1 & \\
\hline David et $a^{75}$ & 2 & \\
\hline De Ajuriaguerra et $a l^{8}$ & 2 & cases 11,12 \\
\hline De Morsier ${ }^{65}$ & 7 & cases $25,26,28,29,30,31,32$ \\
\hline De Reuck et al ${ }^{45}$ & 1 & case 1 \\
\hline Dyck $^{72}$ & 1 & \\
\hline Fenton and $\mathrm{McRae}^{60}$ & 1 & \\
\hline Hammeke et al ${ }^{53}$ & 2 & \\
\hline Hécaen and Ropert ${ }^{42}$ & 19 & $\begin{array}{l}\text { cases } 1,2,3,4,7,8,9,10, \\
14,15,16,20,21,23,24,27 \\
28,30,32\end{array}$ \\
\hline Keschner et al $^{\circ}$ & 4 & \\
\hline Keshavan et al $^{70}$ & 1 & \\
\hline Lennox ${ }^{52}$ & 1 & \\
\hline Mikati et al ${ }^{47}$ & 1 & \\
\hline Miller and Crosby" & 1 & \\
\hline Moniz and Loff ${ }^{68}$ & 1 & \\
\hline Mulder and Daly ${ }^{77}$ & 1 & case 1 \\
\hline Neppe $^{48}$ & 1 & \\
\hline Neumann et al ${ }^{69}$ & 1 & \\
\hline Paillas and Subirana ${ }^{78}$ & 5 & \\
\hline Patterson $^{41}$ & 1 & \\
\hline Penfield and Perot ${ }^{49}$ & 21 & $\begin{array}{l}\text { cases } 6,7,10,12,16,24,29 \\
41,42,43,44,45,46,47,58 \\
59,60,62,63,64,65\end{array}$ \\
\hline Robertson $^{79}$ & 1 & case 9 \\
\hline Riese $^{10}$ & 1 & \\
\hline Saijo et $a l^{o o}$ & 1 & \\
\hline Scott ${ }^{11}$ & 1 & \\
\hline Shapiro et al ${ }^{03}$ & 1 & \\
\hline Tanabe et al ${ }^{15}$ & 1 & \\
\hline Tarachow $^{12}$ & 6 & \\
\hline
\end{tabular}

Elementary and complex AHs may also occur with lesions of the tegmentum of the pons and lower midbrain. ${ }^{56}$ MRI, CT and BAEP, however, failed to disclose a brainstem lesion in our patient, indicating that it was not brainstem auditory hallucinosis. Tanabe $e t$ al $^{15}$ described a patient who developed a transient verbal hallucinosis in the right ear, which lasted for 17 days, as well as fluent aphasia following a left temporal haemorrhagic infarction. CT scans obtained during admission disclosed a low density area with small, high density spots in the left superior temporal gyrus, which was partially enhanced by contrast medium. However, when the hallucinosis had disappeared, the area with abnormal attenuation values was

Table 2 Selected cases of complex AHs of central origin (Letters refer to authors' initials, followed by their patient's case number)

\begin{tabular}{llllll}
\hline \multirow{2}{*}{ Type of perceptions } & \multicolumn{2}{l}{ Spontaneous lesion } & & \multicolumn{2}{l}{ Experimental stimulus } \\
\cline { 2 - 3 } \cline { 5 - 6 } Might & Left & & & Right & Left \\
\hline Musical, songs & & PP46 & & PP5, PP9 & PP11 \\
& & HR15 & & PP17 & PP31 \\
Verbal, voices & PP29 & D1 & & PP30 & \\
& & PP43 & & PP3, PP7 & PP12 \\
& & PP44 & & PP8, PP15 & \\
& & DM25 & & PP16, PP28 & \\
& & HR10 & & & \\
Verbal and musical & HR16 & & & \\
& & MP7 & & & PP13 \\
& PP45 & T & & & PP14 \\
\hline
\end{tabular}

$\mathrm{D}=$ David $e t \mathrm{al}^{75} ; \mathrm{DM}=\mathrm{De}$ Morsier ${ }^{65} ; \mathrm{HR}=$ Hécaen and Ropert ${ }^{42} ; \mathrm{ML}=$ Moniz and $\mathrm{D}=$ David et $a l^{75} ; \mathrm{DM}=\mathrm{De}$ Morsier
Loff $^{66} ; \mathrm{PP}=$ Penfield and Perot $^{49} ; \mathrm{T}=$ Tanabe et al ${ }^{15}$ no longer found. A linear, low density area remained at the lateral edge of the left superior temporal gyrus, and enlargement of the left sylvian fissure was noticed.

The concomitant disappearance of both the hyperdensities on the CT scans and the auditory phenomena might suggest that the second of these was caused by the abnormal excitatory effect of the haemorrhagic component of the lesion. According to Berrios, ${ }^{57}$. musical perceptions tend to disappear together with the underlying pathology when associated with strokes. Such an abnormal brain excitability may well have brought forth the unilateral musical perceptions in our patient as well, as there seems to be a parallelism between the course of the phenomena experienced in the left ear and the progressive disappearance on CT of the hyperdense aspect of the right sylvian fissure. Moreover, the lesion location in our patient, as shown by CT and MRI, is consistent with the one described in those patients with unilateral complex AHs that Tanabe et $a l^{15}$ recorded in the literature on unilateral AHs of central origin: the lesions were located around the sylvian fissure and centred on the first temporal convolutions. In the cases reviewed by Tanabe et $a^{15}$ as in our patient, the auditory phenomena were lateralised in the opposite ear to the involved hemisphere. Further evidence of this lateralisation phenomenon in AHs of central origin can be found in Penfield and Perot. ${ }^{49}$ For instance, they induced a voice lateralised in the left ear by stimulating the right temporal cortex of their patient (case 29), and reported a patient (case 45) with left temporal lobe pathology who experienced verbal and musical phenomena in the right hemispace.

The crucial question is whether verbal hallucinosis is associated with left hemisphere, and musical hallucinosis with right hemisphere lesions in right handed individuals. Berrios ${ }^{57}$ expressed the view that the non-dominant hemisphere plays an important role in the generation of musical phenomena in patients with brain lesions, and that this finding fits in well with what is known about music processing in the brain. He also claims that there might be a dissociation between musical perceptions and the putative mechanisms related to hallucinatory voices in schizophrenic subjects, which seem to be associated with the dominant hemisphere. ${ }^{73}$ To evaluate this view, we reviewed 118 patients with spontaneous musical or verbal AHs or both (table 1).

Only those cases with sufficient data on the contents of the hallucinations and the site of lesion were chosen as subjects of investigation. We excluded cases with concomitant convulsive speech acts, concomitant hallucinations in modalities other than the auditory one, concomitant mental disorders, past history of alcohol overconsumption and of mental illness, deafness and ear disease, evidence of bilateral cerebral involvement, insufficient information on handedness, cerebral dominance, or clinical picture. Table 2 gives an overview of the remaining 28 selected cases, according to the type of auditory perceptions, lateralisation 
(right versus left hemisphere) and nature (spontaneous versus experimental condition) of the lesion. No significant differences were found either between left versus right lateralisation of lesion/stimulus and type of auditory phenomena $\left(\mathrm{G}=1.37<\chi^{2}=5.99, \mathrm{p}=0.05\right)$ or between the nature of lesion/stimulus and type of auditory phenomena $\left(\mathrm{G}=1.81<\chi^{2}=\right.$ $5.99, \mathrm{p}=0.05)$. Our analysis indicates that there is no close association between the kind of phenomena experienced (verbal versus musical) and laterality of the lesion, and consequently does not enable us to confirm Berrios,57 conclusions. It supports Hécaen and Albert's ${ }^{80}$ findings that both complex musical and verbal hallucinosis with a clear, external sensory quality can be produced by lesions confined to the same hemisphere.

In conclusion, we reviewed the different clinical conditions that may cause AHs, and compared them with the clinical picture of the patient we described. We retained two major hypotheses to explain the occurrence of her auditory phenomena. Although the clinical evidence favours a neurological aetiology, the occurrence of a concomitant ear disease does not enable us to ignore the possible contributory and precipitating role of the otological factor. Whether the combination of the central and peripheral dysfunction was the necessary condition to cause the patient's musical perceptions remains uncertain. Nevertheless, both the description of our patient and the review of reported cases support the view that, in patients with organic cerebral disease, unilateral $\mathrm{AHs}$ can be considered a significant clinical sign indicating a lesion in the contralateral hemisphere. But we were not able to confirm the hypothesis that, in cases of hemispheric lesion, musical perceptions are related to pathology of the right hemisphere only.

We thank the members and colleagues of the Belgian-Dutch Research Group for Clinical Neuropsychology (P Boon, A
Lormans, PP, HR Van Dongen, M Van Mourik) for their Lormans, PP, HR Van Dongen, $M$ Van Mourik) for their constructive review of the manuscript, $\mathrm{Dr} H$ Tanabe for providing us with additional references and for his friendly and
helpful comments, $\mathrm{Dr} M$ Dumon-Radermecker for commenting on the patient's EEG data, Mrs V Serlet for revising the English text and Mrs I Bats and Mr R Van Hove for the photographic work.

Presented in part at the 13th European Conference of the International Neuropsychological Society, Innsbruck, Austria, 4-7 July 1990.

1 Asaad G, Shapiro B. Hallucinations: theoretical and clinica overview. Am F Psychiatry 1986;143:1088-97.

2 Claude $\mathrm{H}$, Ey $\mathrm{H}$. Evolution des idées sur l'hallucination: position actuelle du problème. Encéphale 1932;27: position

3 Claude $\mathrm{H}$, Ey $\mathrm{H}$. Hallucinose et hallucination: les théories neurologiques des phénomènes psycho-sensoriels. Encéphale 1932;27:576-621.

4 Ey H. Traité des Hallucinations. Paris: Masson, 1973.

5 Cambier J, Decroix JP, Masson C. Hallucinose auditive dans les lésions du tronc cérébral. Rev Neurol 1987; 143:255-62.

6 Cascino GD, Adams RD. Brainstem auditory hallucinosis. Neurology 1986;36:1042-7.

7 Courville CB. Auditory hallucinations provoked by intracranial tumors. Arch Neurol Psychiatry 1928;19:558-64

8 De Ajuriaguerra J, Hécaen H, Sadoun R. Les troubles mentaux au cours des tumeurs de la région mésodiencéphalique. Encéphale 1954;43:406-78.

9 Keschner M, Bender MB, Strauss I. Mental symptoms in cases of tumor of the temporal lobe. Arch Neurol Psychiatry 1936;35:572-96.

10 Riese MW. Craniopharyngiome chez une femme âgée de 57 ans. Hallucinations visuelles et auditives. Deuxième note sur la genèse des hallucinations survenant chez les malades atteints de lésions cérébrales. Rev Neurol 1950;82:137-9.

11 Scott $M$. Musical hallucinations from meningioma. $\mathcal{F} A M A$ 1979;241:1683.

12 Tarachow $S$. The clinical value of hallucinations in localizing brain tumours. Am $\mathcal{F}$ Psychiatry 1941;97:1434-42.

13 Ross ED, Jossman PB, Bell B, Sabin T, Geschwind N Musical hallucinations in deafness. $\mathcal{f} A M A$ 1975;231: 620-2.

14 Gruber LN, Mangat BS, Abou-Taleb H. Laterality of auditory hallucinations in psychiatric patients. Am $\mathcal{J}$ Psychiatry 1984;141:586-8.

15 Tanabe H, Sawada T, Asai H, Okuda J, Shiraishi J Lateralization phenomenon of complex auditory hallucinations. Acta Psychiatr Scand 1986;74:178-82.

16 Aizenberg D, Schwartz B, Modai I. Musical hallucinations acquired deafness and depression. $\mathcal{f}$ Nerv Ment Dis 1986;174:309-11.

17 Barta PE, Pearlson GD, Powers RE, Richards SS, Tune LE. Auditory hallucinations and smaller superior temporal gyral volume in schizophrenia. Am $\mathcal{F}$ Psychiatry 1990; 147:1457-62.

18 Chiu LP. Transient recurrence of auditory hallucinations during acute dystonia. Br ₹ Psychiatry 1989;155:110-3.

19 Cleghorn JM, Garnett ES, Nahmias C et al. Regional brain metabolism during auditory hallucinations in chronic chizophrenia. Br f Psychiatry 1990;157:562-70.

20 Collins MN, Cull CA, Sireling L. Pilot study of treatment of persistent auditory hallucinations by modified auditory input. $\mathrm{Br} M e d \mathcal{F} 1989 ; 299: 431-2$.

21 Friedman EH. Auditory hallucinations during oculogyric crises. Br f Psychiatry 1990;156:746-7.

22 Green MF, Kinsbourne M. Subvocal activity and auditory hallucinations: clues for behavioral treatments? Schizophr Bull 1990;16:617-25.

23 Lindstrom L, Klockhoff I, Svedberg A, Bergstrom K. Abnormal auditory brainstem responses in hallucinating schizophrenic patients. Br f Psychiatry 1987;151:9-14.

$24 \mathrm{Matsuda} \mathrm{H}$, Gyobu T, Ii M, Hisada K. Increased accumulation of $\mathrm{N}$-isopropyl-(I-123) p-iodoamphetamine in the left auditory area in a schizophrenic patient with auditory left auditory area in a schizophrenic patient with

25 McInnis M, Marks I. Audiotape therapy for persistent auditory hallucinations. Br $\mathcal{F}$ Psychiatry 1990;157:913-4. 26 McKay SE, Golden CJ, Scott M. Neuropsychological correlates of auditory and visual hallucinations. Int $\mathcal{f}$ Neurosci 1981;15:87-94

27 Nelson HE, Thrasher S, Barnes TR. Practical ways of alleviating auditory hallucinations. $B r$ Med $\mathcal{f} 1991$; 302:327.

28 Rogers DG. Oculogyric crises and schizophrenia. $\mathrm{Br} f$ Psychiatry 1989;155:569-70.

29 Waldfogel S, Mueser KT. Another case of chronic PTSD with auditory hallucinations. Am $f$ Psychiatry 1988; 145: 1314 .

30 Wengel SP, Burke WJ, Holemon D. Musical hallucinations: the sound of silence? 7 Am Geriatr Soc 1989;37:163-6.

31 Glass IB. Alcoholic hallucinosis: a psychiatric enigma-1. The development of an idea. $\mathrm{Br} f$ Addict 1989;84: $29-41$.

32 Matsuda H, Gyobu T, Ii M, Hisada K. Iodine-123 iodoamphetamine brain scan in a patient with auditory hallucination. $\mathcal{f}$ Nucl Med 1988;29:558-60.

33 Scott RT. Hallucinations of music in alcohol withdrawal. Neurology 1975;25:362.

34 Treloar A, Crook M, Parker L, Doing R. Hypophosphataemia, hallucinations, and delirium tremens. Lancet 1991 ; 338: $1467-8$.

35 Victor M. Mental disorders due to alcoholism. In: Shepherd M, ed. Handbook of psychiatry. Cambridge: Cambridge University Press, 1983:189-211.

36 Allen JR. Salicylate-induced musical perceptions. $N$ Engl f Med 1985;313:642-3.

37 Anderson NR, Tandon DS. Ifosfamide extrapyramidal neurotoxicity. Cancer 1991;68:72-5.

38 Chan CY, Wallander KA. Diphenhydramine toxicity in three children with varicella-zoster infection. Drug Intell Clin Pharm 1991;25:130-2.

39 Miller NS, Gold MS. Organic solvent and aerosol abuse. Am Fam Physician 1991;44:183-9.

40 Paraskevaides EC. Near fatal auditory hallucinations after buprenorphine. $\mathrm{Br} \mathrm{Med}$ f 1988;296:214.

41 Patterson JF. Auditory hallucinations induced by prazosin. $\mathcal{F}$ Clin Psychopharmacol 1988;8:228.

42 Hécaen $\mathrm{H}$, Ropert R. Hallucinations auditives au cours de syndromes neurologiques. Ann Med Psychol 1959;117: 257-306.

43 Bana DS, Graham JR. Observations on prodromes of classic migraine in a headache clinic population. Headache 1986;

44 Ardila A, Sanchez E. Neuropsychologic symptoms in the migraine syndrome. Cephalalgia 1988;8:67-70.

45 De Reuck J, Van Aken J, Van Landegem W, Vakaet A Positron emission tomography studies of changes in cerebral blood flow and oxygen metabolism in arteriovenous malformation of the brain. Eur Neurol 1989, 29:294-7.

46 King D, Brooks DN, Malster MG. "Auditory hallucinations" from a hearing aid? $\mathrm{Br}$ Med $\mathcal{f} 1989 ; 299: 1141$.

47 Mikati MA, Wei Ling Lee, DeLong GR. Protracted epileptiform encephalopathy: an unusual form of partial complex status epilepticus. Epilepsia 1985;26:563-71.

48 Neppe VM. Tape recording auditory hallucinations. Am $f$ 
Psychiatry 1988;145:1316.

49 Penfield W, Perot P. The brain's record of auditory and visual experience. Brain 1963;86:595-697.

50 Rozanski J, Rosen H. Musical hallucinosis in otosclerosis. Conf Neurol 1952;12:49-54.

51 Miller TC, Crosby TW. Musical hallucinations in a deaf elderly patient. Ann Neurol 1979;5:301-2.

52 Lennox G. Auditory hallucinations due to ear disease. $\mathrm{Br} \mathcal{F}$ Psychiarry 1988;153:713 4

53 Hammeke TA, McQuillen MP, Cohen BA. Musical hallucinations associated with acquired deafness. $f$ Neurol nations associated with acquired

54 Hécaen H, Ropert R. Les hallucinations auditives des otopathes. F Psychol Norm Pathol 1963;60:293-324

55 Bryant WS. The great psychical importance of ear disease. $f$ Nerv Ment Dis 1906;33:553-65.

56 Bergman PS. Unilateral auditory hallucinations. Trans Am Neurol Assoc 1965;90:226-7.

57 Berrios GE. Musical hallucinations: a historical and clinical study. Br F Psychiatry 1990;156:188-94.

58 The Sound Lotto Test. Wisbech: Learning Development Aids, 1976.

59 Raven JC. Standard progressive matrices. London: Lewis \& Co. Ltd, 1958.

60 Fenton GW, McRae DA. Musical hallucinations in a deaf elderly woman. Br f Psychiatry 1989;155:401-3.

61 Khan AM, Clark T, Oyebode F. Unilateral auditory hallucinations. Br F Psychiatry 1988;152:297-8.

62 Ross ED. Musical hallucinations in deafness revisited. fAMA 1978;240:1716.

63 Shapiro CM, Kasem H, Tewari S. My music: a case of musical reminiscence diagnosed courtesy of the BBC. $f$ Neurol Neurosurg Psychiatry 1991;54:88-9.

64 Robinson GW. Aural disease in the insane. I Neurol Psychopathol 1927;7:332-7.

65 De Morsier G. Les hallucinations: étude oto-neuro-ophtalmologique Rev Oto Neuro Ophtalmol 1938;16:241-352.

66 Moniz E, Loff $R$. Les hallucinations auditives verbales dans un cas d'astrocytome du lobe temporal gauche. Encéphale 1935;30:20-9.
67 Berthier M, Starkstein S. Acute atypical psychosis following a right hemisphere stroke. Acta Neurol Belg 1987; 87:125-31

68 Cummings JL, Miller B, Hill MA, Neshkes R. Neuropsychiatric aspects of multi-infarct dementia and dementia of the Alzheimer type. Arch Neurol 1987;44:389-93.

69 Neumann PE, Mehler MF, Horoupian DS, Merriam AE. Atypical psychosis with disseminated subpial demyelination. Arch Neurol 1988;45:634-6.

70 Saijo T, Naito E, Ito M, Takeda E, Hashimoto T, Kuroda Y. Therapeutic effect of sodium dichloroacetate on visual and auditory hallucinations in a patient with MELAS. and auditory hallucinations in

71 Bakchine S, Duyckaerts C, Hassine L, et al. Lésions neurologiques centrales et périphériques au cours d'un syndrome de Gougerot-Sjogren primitif: étude clinicopathologique d'un cas. Rev Neurol 1991;147:368-75.

72 Dyck P. Sylvian lipoma causing auditory hallucinations: case report. Neurosurgery 1985;16:64-7.

73 Bazhin EF, Wasserman LI, Tonkonogii IM. Auditory hallucinations and left temporal lobe pathology. Neuropsychologia 1975;13:481-7.

74 Boza RA, Liggett SB. Pseudohallucinations: radio reception through shrapnel fragments. Am $\mathcal{f}$ Psychiatry 1981; 138:1263-4.

75 David MM, Hécaen $H$, Couloniou $R$ Hallucinations auditives sans délire par affections neurologiques. Ann auditives sans delire par affection

76 Keshavan MS, Kahn EM, Brar JS. Musical hallucinations following removal of a right frontal meningioma. $\mathcal{f}$ Neurol Neurosurg Psychiatry 1988;51:1235-6.

77 Mulder DW, Daly D. Psychiatric symptoms associated with lesions of temporal lobe. $\mathcal{F A M A} 1952 ; 150: 173-6$.

78 Paillas JE, Subirana A. Séméiologie neuro-psychique. Rev Oto Neuro Ophtalmol 1950;22:123-218.

79 Robertson A. Unilateral hallucinations: their relative frequency, associations, and pathology. F Ment Sci 1901 47:277-93.

80 Hécaen H, Albert ML. Human Neuropsychology. New York: Wiley, 1978. 